\title{
Clinical Drug Trials on Human Beings viz-a-viz Sanctions related to Animal Experimentation: Need to do Introspection?
}

\author{
Chander Shekhar Gautam, Roosy Aulakh, Prabhjot Singh Cheema
}

\begin{abstract}
Health care law is totally localized in its nature, but research for the development of new drugs has crossed man-made geographical limits. Weaker legal sanctions, poverty, illiteracy and inaccessibility to legal system have all contributed to make India a favored hub for contact research organizations. Many recent clinical drug trials in India have sparked controversy. However, in India today, we are more bothered about animal protection, but show little concern for volunteers in human trials. It is gradually becoming difficult to conduct research on animals; however, research on human beings is far easier. Sanctions against violation of rights of human volunteers in clinical trials are often only a perceived phenomenon. They are not protected as they should be. Regulatory framework needs thorough introspection, debate, reconsideration and strict implementation. These guidelines should not only be recommendatory but mandatory in nature and those who indulge in violations, shall be punished as per the law of the land effectively.
\end{abstract}

Keywords: Clinical research, Animal welfare act, Drug and cosmetics act.

How to cite this article: Gautam CS, Aulakh R, Cheema PS. Clinical Drug Trials on Human Beings viz-a-viz Sanctions related to Animal Experimentation: Need to do Introspection? J Postgrad Med Edu Res 2012;46(3):113-116.

\section{Source of support: Nil}

Conflict of interest: None declared

\section{INTRODUCTION}

Clinical research is mandatory to find out the new treatments for the diseases of the modern world with a binding that research would take care about the ethical component and rationality in a civilized world on civilized society in a civilized manner. Health care law is totally localized in its nature, but research for the development of new drugs has crossed man-made geographical limits. ${ }^{1}$ The developing nations have become a soft target, where despite efforts only few new molecules of drugs are found; hence, such nations have become a hub of contract research organizations (CROs). ${ }^{2}$ In case of any adverse event during a trial, it is becoming increasingly difficult to hold such international companies which are getting their trials done through CROs of the developing nations accountable and liable. If such clinical trials on human subjects fall under the ambit of 'fiduciary relationship', then why as per the Law of Tort it is not amounting to negligence, in case of serious consequences related to subjects of the drug trials?
Moreover, the liabilities of drug companies also arise, when we apply the principle of 'vicarious liability'.

As per general principles of law and rules of natural justice, human being is conferred with certain basic human rights which are reaffirmed under tenets of Universal Human Rights, 1948. The conduct of clinical trials without informed consent on the prisoners of war in Second World War by Germans led to the birth of Nuremberg Code in 1947 whereby it was declared inhuman to try newer drugs on prisoners of war. ${ }^{3}$ Importance of consent was recognized which was later reflected in subsequent declarations of Helsinki, to which whole world agreed in principles under various treaties of Public International Law. ${ }^{4}$

Whenever human subjects are enrolled in a clinical drug trial, a fiduciary relationship arises among the researchers and the volunteers, giving rise to rights and duties. So, whenever there is breach of duties, it will automatically become the basis of right to claim compensation under tort of negligence. Hence, whenever there is breach of duty on part of researcher, volunteer can make him liable or through him, drug company can be made vicariously liable. Thereby, duty, breach of duty on part of researcher(s), damages to volunteer's interest and compensation in lieu of the damages are all components of Law of Tort. Hence, even the provisions of company laws need to be amended to safeguard the interests of such volunteers who are largely poor, illiterate and ignorant of their fundamental rights in India.

When the consent is taken from volunteer of clinical trial for the participation with the promise that such individual will get drug supply uninterrupted even once the trial is over; the inability of providing that drug to such individual is violation of 'promissory estoppels' under section 115 Indian Evidence Act 1872. Whatever is promised must be fulfilled subsequently.

\section{WHY THESE SITUATIONS ARE COMING TO FOREFRONT?}

The Patents (Amendment) Act 2005, Drug and Cosmetics (II Amendment) Rules 2005 and allowance by FDA to submit data collected in developing countries for drug approval process in addition to low cost of conducting clinical trials in India have all contributed to make India 
favored hub. ${ }^{5-7}$ Moreover, poverty, illiteracy, weaker regulations and inaccessibility to legal system allow multinational companies to escape from paying compensation in case of any inadvertent adverse effects during clinical trials.

\section{LEGAL FRAMEWORK AVAILABLE}

Under the International law, there are treaties governing the clinical trials for example Nuremberg Code, Helsinki declaration, Human rights related declarations, International Conference on Harmonisation (ICH)/WHO Good Clinical Practice (ICH-GCP), WHO guidelines and so on. Based on these guidelines given under these treaties/declarations in India, there are Indian Council of Medical Research (ICMR) guidelines, Department of Biotechnology (DBT) guidelines, GCP guidelines 2001, Genetic guidelines and so on. Rights of individual are even protected under the Constitution of India (Article 21), Right to Information Act 2005, and finally Drug and Cosmetics Act 1940 and then second amendment rules 2005 under Drug and Cosmetics Act. After the Bhopal gas tragedy, now there is relevance of Environmental Protection Act 1986 and Public Assurance Policy 1992 under Environmental Protection Act 1986. Guidelines related to clinical trials in India are being governed by ICMR which highlight the importance of independent ethics committees; informed consent, reimbursement, compensation in case of adverse events and provision of drugs after completion of clinical trial.

\section{CONTROVERSIAL TRIALS IN INDIA}

Many recent clinical drug trials in India have sparked controversy bringing few issues from backdrop to forefront:

Clinical trials without informed consent: Annoyed at the nonsubmission of reports with regard to unauthorized clinical drug (exemestane) trials on 25 poor women in Andhra Pradesh without informed consent, the National Human Rights Commission (NHRC) on 19th March 2012 asked the health ministry and state officials to respond within 6 weeks or face action under the law. ${ }^{8}$

Independent ethics committee vs institutional ethics committee: Government doctors of a mental hospital attached to Mahatma Gandhi Medical College in Indore, Madhya Pradesh, did trials (2008-10) to check effectiveness of dapoxetine in treating premature ejaculation by taking permission from independent ethics committees of private hospitals and not the Institutional ethics committee of said medical college. ${ }^{9}$

Clinical trials comparing controversial drugs with safer drugs: The 'TIDE Trial' a GlaxoSmithKline (GSK) sponsored double-blind trial comparing Avandia with Actos, made by Takeda Pharmaceuticals was undertaken despite claims by Cleveland Clinic cardiologist in 2007 suggesting that the drug harmed the heart. FDA issued a warning but ironically FDA oversight board voted 8 to 7 to accept the advice of a committee of independent experts to let the drug remain in the market. Though, the later sequences of events were quite predictable with Indian government ordering GSK to suspend 19 drug trials in India on 30th June 2010; the number of patients who suffered in these trials largely remains unknown. Actions taken were at sharp contrast in India where the FDA ordered GSK to stop enrolling people in a controversial clinical trial comparing diabetes drugs, and to notify more than 1,300 people already undergoing tests that they may be at greater risk for heart attacks because they have taken Avandia while company settled a lawsuit with 2,132 plaintiffs who claimed that Avandia caused heart attacks and strokes for $\$ 460$ million as per claims by a California-based lawyer. ${ }^{10}$

Bioequivalence studies: In 2002, investigation following death of a daily wage worker who was given a psychiatric drug as part of a bioequivalence study sponsored by the Mumbai-based Sun Pharmaceuticals suggested that the participants were unlikely to have been able to give their voluntary informed consent to participate. Incidentally, bioequivalence studies are conducted by drug exporters to prove that their product is as effective as the approved branded version. They are not needed by Indian regulatory authorities. $^{11}$

Research in emergency situations without informed consent: In 2003 to 2004, investigation following death of eight elderly patients during bioequivalence study conducted by Santa Biotech testing its streptokinase against the established revealed that trial protocol was not reviewed by an ethical review committee and informed consent was not obtained. Litigation was filed by the Delhi-based NGO Aadar Destitute and Old People's home. In March 2004, the Hon'able Supreme Court of India confirmed that the trials had been illegal. ${ }^{12,13}$

Stopping standard treatment and replacing it with placebo: Johnson and Johnson sponsored trial comparing risperidone with placebo (2004) generated controversy because the patients receiving a placebo could suffer unnecessary harm by being taken off their medication. ${ }^{14,15}$

Phase III trials prior to completion of Phase II trials: The Drugs Controller General of India (DCGI) approved Phase III trial of Pfizer's Zoniporide while Phase II trials had not been completed in the USA and carcinogenic and reproductive studies on animals as mandated by Indian law had not been completed. ${ }^{16}$ 
Human trials prior to safety trials in animals: In a Johns Hopkins Hospital (US) sponsored trial, NDGA (nordihydroguaiaretic acid) was tried on 26 oral cancer patients in Trivandrum at Regional Cancer treatment Center (RCC), India, before its safety was established in animal tests. ${ }^{17,18}$

Variation in compensation for Indian vs foreign volunteers: In what has been described as 'dollar rain' by the Nigerian press, Pfizer paid ₹ 91,00,000/- in August 2011 to each of the next of kin of four children who died during clinical trials of the drug Trovan in Nigeria that began in 1996. This is in contrast this with what the company paid to its Indian victims. According to data released by the Ministry of Health and Family Welfare, the maximum compensation paid by the company this year for death during clinical trial in 2010 was $₹ 225,000 /-.{ }^{19}$

Trials on children with drugs approved for adults: In reply to a right to information (RTI) query 2008, the AIIMS said that 49 babies had died during clinical trials over two-anda-half year period. Two of the trial drugs-olmesartan and valsartan, meant for reducing blood pressure-have never been tried on patients below the age of 18 years, the Monthly Index of Medical Specialties editor Chandra M Gulhati said. $^{20}$

\section{GUIDELINES FOR HUMAN TRIALS LACKING THE CANINES}

However, the ICMR guidelines have weak legal sanctions. According to Dr VM Katoch, Director General, ICMR, low costs, weak laws and inadequate enforcement and penalties can be blamed for the present state of affairs. ${ }^{21}$ The ethics committees are improperly constituted, privately managed, decentralized and have researchers of these trials as their members thereby generating conflict of interest. Though, the Clinical Trials Registry-India (CTRI), a welcomed initiative by ICMR, has been made mandatory with effect from 15th June $2009^{22}$ lack of central registry of ethical committees allows numerous unethical trials rejected by IRBs to get accepted by other private ethics committees. Many a times, the so called 'healthy' volunteers recruited by CROs in various trials fail to be so and suffer adverse outcome. There is no provision as to who declares them to be 'healthy' prior to recruitment. An infant in Bangalore, who had a pre-existing cardiac disorder, died during a Wyeth sponsored clinical trial for an advanced pneumonia vaccine. ${ }^{23}$ According to Drugs Controller General India (DCGI), the 'inclusion-exclusion' criteria protocol was not adhered to by the investigator. Participation of a volunteer in multiple clinical trials without mandatory 3 months wash- off period is not uncommon practice. There is no independent review board to conduct enquiry in case of any adverse events during such trials, which is left all to the discretion of the sponsoring multinational company. Furthermore, the amount of compensation is not fixed nor it is applicable to private doctors conducting clinical trials. Though there has been tremendous increase in number of CROs in India, no rules and regulations have been framed to keep them under scrutiny. These agencies shove off any responsibility if any untoward event occurs during trials. There is no grievance reprisal forum for victims of these trials and vast majority of illiterate, ignorant and poor citizens of India are unaware of whom to contact in case of any complaints: The treating physician cum researcher/ institute head/CRO/sponsoring multinational company/ marketing company/NHRC/DCGI or the media.

However, in India today, we are more bothered about animal protection but show little concern for volunteers in human trials. It is gradually becoming difficult to conduct research on animals; however, research on human beings is far easier. Though such volunteers of clinical drug trials are considered as guinea pigs (despite equating them to animals, they are not protected like the animals), thanks to Committee for the Purpose of Control and Supervision of Experiments on Animals (CPCSEA) and People for the Ethical Treatment of Animals (PETA) for their continuous pressure and pursuance in implementing the legal sanctions against erring individuals/agencies through court of law.

The Animal Welfare Act 2011 clearly states that (a) contravention of section 21 or any order made by Committee under section 27 or (b) commitment of breach of any requirement/condition imposed by the committee under those sections shall be punishable with fine not less than ₹ 20,000/- and may extend to ₹ 50,000/- or imprisonment which shall not be less than 1 year but may extend to 3 years or with both. In case of second and subsequent offence, fine of ₹ 75,000/- and may extend to 1 Lac and imprisonment not less than 2 years which may extend to 5 years. If such breach occurs within an institution, the person in charge of such an institute shall also be deemed to be jointly guilty of the offence and punished according to the Act. If there is need to enhance the penalties prescribed, Government can do so by notification in the official gazette. However, according to the news item from Times of India July 3, 2011, the offender could end up paying up to ₹ 1 crore fine or be jailed for 5 years as proposed by Environment and Forests ministry in Animal Welfare Bill 2011. For institutions or companies, the penalty could be even ₹ 25 crores. $^{24}$

However, sanctions against violation of rights of human volunteers in clinical trials are often only a perceived 
phenomenon. They are not protected as they should be. Government shall enact the law on similar lines so that these guinea pigs of clinical trials are protected and safeguarded. Regulatory framework needs thorough introspection, debate, reconsideration and strict implementation. These guidelines should not only be recommendatory but mandatory in nature and those who indulge in violations, shall be punished as per the law of the land effectively.

\section{REFERENCES}

1. Sinha G. Outsourcing drug work. Pharmaceuticals ship R and D and clinical trials to India. Sci Am 2004 Aug;291(2):24-25.

2. Lee A. Regulations failing to keep up with India's trials boom. Lancet 2012 Feb 4;379(9814):397-98.

3. Reprint from trials of war criminals before the Nuremberg Military Tribunals under Control Council Law 10(2):181-82. Washington DC: US Government Printing Office, 1949. Available at: http://ohsr.od.nih.gov/guidelines/nuremberg.html

4. Kapoor SK. Definition of International Law. In: Kapoor SK, (Ed). International Law and Human Rights (16th ed). Ajanta Offset Press, Allahabad, India 2007;24-32.

5. Bhatt A. Indian clinical trials: Paradigm shift from speed to quality? Perspect Clin Res 2012 Jan-Mar 3(1):1-3.

6. Gupta YK, Padhy BM. India's growing participation in global clinical trials. Trends Pharmacol Sci 2011 Jun;32(6): 327-29.

7. Varawalla N. India's growing clinical research sector: Opportunity for global companies. Drugs 2007 Jun;10(6):391-94.

8. Hona'ble Supreme Court of India notice to Centre on illegal drug trials in India. The Tribune, New Delhi, 2012, March 19.

9. Gaur A. Sexual malfunction drug tried out on mentally ill patients in Indore. Times of India, 2011, Dec 20.

10. $\$ 460,000,000$ Settlement in diabetes drug (Avandia) lawsuit. The New York Times. Gaithersburg, Md July 14, 2010.

11. Srinivasan S. Ethical concerns in clinical trials in India: An investigation. Centre for studies in ethics and rights, Mumbai, India 2009, Feb.

12. Basu I. India's clinical trials and tribulations. Asia Times, 2004, 23 Jul, Available at: http://www.atimes.com/atimes/ South_Asia/FG23Df03.html (Apr 2006).
13. Srinivasan S. Indian guinea pigs for sale: Outsourcing clinical trials. India Resource Center, 2004, 8 Sep. Available at: http:// www. infochangeindia.org/features304.jsp (Apr 2006).

14. Srinivasan S, Pai SA, Bhan A, et al. Trials of risperidone in India-concerns. Bri J Psychiatry 2006 May;188:489-92.

15. Drug trials outsourced to India. BBC News, 22 Apr 2006. Available at: http://news.bbc.co.uk/2/hi/south_asia/4932188.stm (Jun 2006).

16. Gulhati CM. Needed: Closer scrutiny of clinical trials. Indian J Med Ethics 2004 Jan-Mar1(1):4-5.

17. Mudur G. Johns hopkins admits scientist used Indian patients as guinea pigs. BMJ 2001;24 Nov 323(7323):1204.

18. Mudur $\mathrm{G}$. Indian doctors defend unethical anticancer drug trial. BMJ 2001 Aug 11;323-399.

19. Singh A. Pfizer dollar rain in Nigeria, are scarce in India. The sunday guardian. New Delhi 2011 Dec 11.

20. Inquiry launched into Indian drug trials. Nature 2008;454:1041.

21. Gautam CS, Sharma S. Trial travails. The Tribune, Chandigarh, India 2012 Feb 9, 9(col1).

22. Clinical Trials Registry India. Available from: http:// www.ctri.in.

23. Wyeth clarifies on child's death during drug trial. Times of India 2009 Mar 4.

24. The Animal Welfare Act, 2011. Animal Welfare Board of India.

\section{ABOUT THE AUTHORS}

\section{Chander Shekhar Gautam (Corresponding Author)}

Professor and Head, Department of Pharmacology, Government Medical College and Hospital, Chandigarh-160030, India Phone: 91-9646121603, e-mail: csgautam_06@yahoo.co.in

\section{Roosy Aulakh}

Assistant Professor, Department of Pediatrics, Government Medical College and Hospital, Chandigarh, India

\section{Prabhjot Singh Cheema}

Assistant Professor, Department of Law, Rayat and Bahra College of Law, Mohali, Punjab, India 